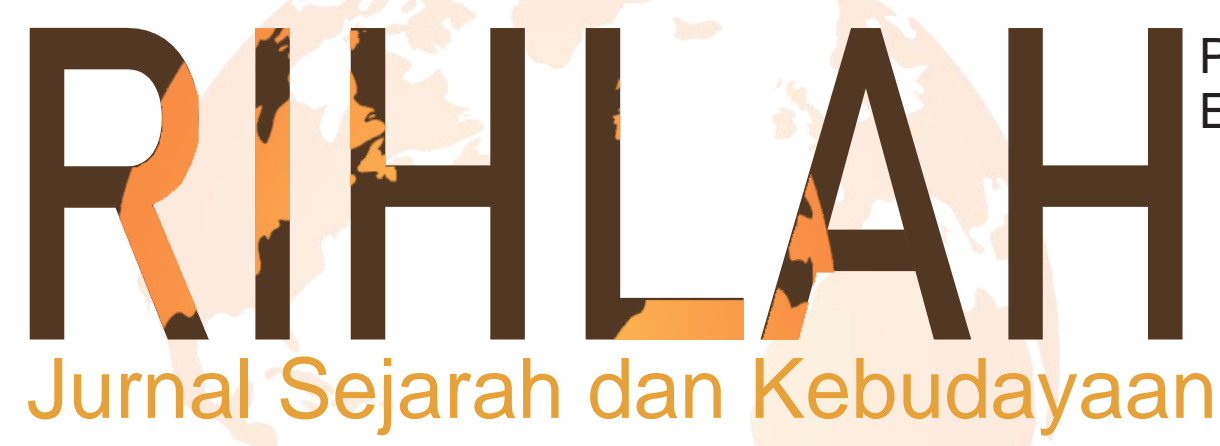

P-ISSN: 2339-0921

E-ISSN: 2580-5762

Pengaruh Bugis di Tanah Melayu dalam Perspektif Sejarah Sosial Politik Saepuddin

Akulturasi Budaya: Adat Pernikahan di Kelurahan Cikoro Kecamatan Tompobulu Kabupaten Gowa St. Hajar, M. Dahlan M, Syamzan Syukur

Corry Van Stenus, Perempuan dalam Perjuangan Abdul Qahhar Mudzakkar (1950-1965) Nurul Azizah

Sejarah dan Penyebaran Islam di Asia dan Afrika Herman Wicaksono

Sarekat Islam Penggagas Nasionalisme di Indonesia Soraya Rasyid, Annisa Tamara

Bergerak dengan Dua Sayap: Fenomena Gerakan Dakwah dan Politik Hizbut Tahrir di Indonesia Pasca Reformasi Aksa 


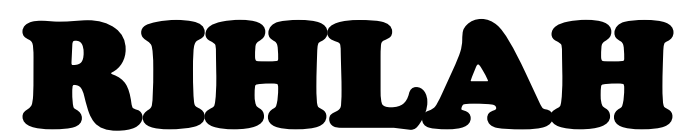

Jurnal Sejarah dan Kebudayaan

\begin{tabular}{|c|c|}
\hline Editor in Chief & : Dr. Rahmat, M.Pd. \\
\hline Managing Editor & : Mastanning, S.Hum, M.Hum. \\
\hline Editorial Board & $\begin{array}{l}\text { : Nur Ahsan Syukur, S.Ag, M.Si. } \\
\text { : Chaerul Munzir, S.Hum, M.Hum. } \\
\text { : Lydia Megawati, S.Hum, M.Hum. } \\
\text { : Muhammad Husni, S.Hum, M.Hum. } \\
\text { : Zaenal Abidin, S.S., M.H.I. } \\
\text { : Chusnul Chatimah Asmad, S.IP, M.M. } \\
\text { : Muhammad Arif, S.Hum, M.Hum. } \\
\text { : Nurhidayat, S.Hum, M.Hum. }\end{array}$ \\
\hline Desain Grafis & : Nur Arifin, S.IP. \\
\hline Secretariat & : Safaruddin, S.Hum. \\
\hline Reviewers & $\begin{array}{l}\text { : Prof. Dr. H. Abd. Rahim Yunus, M.A. } \\
\text { : Prof. Dr. H. Ahmad M. Sewang, M.Ag. } \\
\text { : Dr. Hj Syamzan Syukur, M.Ag. } \\
\text { : Dr. Nasruddin Ibrahim. } \\
\text { : Dr. Abd. Rahman Hamid. } \\
\text { : St. Junaeda, M.Hum. } \\
\text { : Dr. Rahmawati, MA. } \\
\text { : Dr. Nurhayati Syairuddin, M.Hum }\end{array}$ \\
\hline
\end{tabular}

Alamat Redaksi dan Tata Usaha : Jurusan Sejarah dan Kebudayaan Islam Fakultas Adab dan Humaniora UIN Alauddin Makassar, Jln. Sultan Alauddin No. 36 Samata Gowa Tlp. 0411-841879 Fax.0411-822140 (Kampus II) E.Mail. rihlah@uin-alauddin.ac.id

Jurnal Rihlah terbit dua kali dalam setahun, bulan Juni dan bulan Desember berisi kajian tentang Sejarah dan Kebudayaan, baik dari hasil penelitian maupun tulisan ilmiah lainnya.

Penyunting menerima tulisan yang belum pernah diterbitkan oleh media cetak lain. Naskah diketik spasi $1 \mathrm{~cm}$ pada kertas berukuran A4 dengan tulisan berkisar 12-23 halaman. Naskah yang masuk dievaluasi oleh Dewan Penyunting. Penyunting dapat melakukan perubahan pada tulisan yang dimuat untuk keseraganan format, tanpa mengubah maksud dan konten tulisan. 
Saepuddin $01-17$

Pengaruh Bugis di Tanah Melayu dalam Perspektif Sejarah Sosial Politik

St. Hajar, M. Dahlan M, Syamzan Syukur

Akulturasi Budaya: Adat Pernikahan di

Kelurahan Cikoro Kecamatan Tompobulu

Kabupaten Gowa

Nurul Azizah.

Corry Van Stenus, Perempuan dalam Perjuangan

Abdul Qahhar Mudzakkar (1950-1965)

Herman Wicaksono.

Sejarah dan Penyebaran Islam di Asia dan Afrika

Soraya Rasyid, Annisa Tamara

$66-84$

Sarekat Islam Penggagas Nasionalisme di Indonesia

Aksa

Bergerak dengan Dua Sayap: Fenomena Gerakan Dakwah

dan Politik Hizbut Tahrir di Indonesia Pasca Reformasi 


\title{
Corry Van Stenus, Perempuan dalam Perjuangan Abdul Qahhar Mudzakkar $1950-1965^{1}$
}

\author{
Nurul Azizah \\ Universitas Islam Negeri Sunan Kalijaga Yogyakarta \\ nurulazizah097@gmail.com
}

\section{Abstract}

Rebellion is often identified as a masculine realm, which is dominated by men. But in the case of Kahar Mudzakkar's rebellion in South Sulawesi, we could find a women named, Corry Van Stenus,.she was a Javanese-Dutch German and also the second wife of Kahar Mudzakkar. This paper focuses on Corry's life during the Kahar Mudzakkar rebellion. This theme is rarely discussed because the writings on rebellion are dominated by men. By using the historical approach, this paper wants to show about women in rebellion. in this case, Corry and her role as a woman, wife and mother in a rebellion. In conclusion, Corry became a woman who played a role in Kahar Mudzakkar's rebellion. From the domestic sphere, she became the wife and mother who accompanied her husband in rebellion. From the political realm, she became a lead of the Sulawesi Islamic Women's Movement (GERWAIS).

Keywords: Corry Van Stenus, Woman, Rebellion of Kahar Mudzakkar

\section{Abstrak}

Pemberontakan seringkali diidentikan sebagai ranah maskulin, yang didominasi oleh laki-laki. Namun dalam kasus pemberontakan Kahar Mudzakkar di Sulawesi Selatan, dapat ditemukan nama seorang perempuan yang turut secara aktif berperan yakni Corry Van Stenus. Ia merupakan perempuan keturunan JawaBelanda Jerman yang merupakan istri kedua Kahar Mudzakkar. Tulisan ini berfokus pada kehidupan Corry selama pemberontakan Kahar Mudzakkar terjadi. Tema ini jarang dibahas karena tulisan-tulisan mengenai pemberontakan cenderung berisi mengenai tokoh utama pemberontakan yang biasanya adalah laki-laki. Dengan menggunakan pendekatan sejarah tulisan ini ingin menunjukkan mengenai sosok Corry dan peranannya sebagai perempuan, istri dan juga seorang ibu dalam sebuah pemberontakan. Sebagai kesimpulan, Corry menjadi perempuan yang ikut secara aktif berperan dalam pemberontakan Kahar Mudzakkar. Dari aspek domestik, ia menjadi istri dan ibu yang menemani suaminya dalam pemberontakan. Sedangkan dari aspek politik, ia menjadi Ketua Gerakan Wanita Islam Sulawesi (GERWAIS).

Kata kunci : Corry Van Stenus, Perempuan, Pemberontakan Kahar Mudzakkar

${ }^{1}$ Tulisan ini merupakan bagian dari Nurul Azizah. "Biografi Cornelia Van Stenus : 19472006 ”, skripsi, program studi Ilmu Sejarah Fakultas Ilmu budaya Universitas gadjah Mada Yogyakarta. 2018. 


\section{Pendahuluan}

Terdapat banyak tulisan yang merekonstruksi pemberontakan Abdul Qahhar Mudzakkar Kahar Muzakka di Sulawesi Selatan. ${ }^{2}$ Meskipun tema ini populer, tulisan-tulisan yang hadir kebanyakan hanya membahas mengenai pribadi Kahar Muzakkar, pemikirannya dan hubungannya dengan gerakan Darul Islam, Kartosuwirjo. Beberapa tulisan kemudian muncul untuk membahas peristiwa ini dari prespektif orang lain selain Kahar. Biasanya tulisan tersebut menulis mengenai lawan politik Kahar Muzakkar yang pada umumnya berjenis kelamin laki-laki.

Peridoe ini, belum terdapat karya yang ditulis untuk membahas mengenai perempuan yang terlibat dalam pemberontakan Kahar. Padahal dalam tulisantulisan yang membahas gerakan Kahar seringkali dituliskan mengenai adanya usaha dari Darul Islam/ Tentara Islam Indonesia DI/TII di Sulawesi Selatan untuk meraih simpati perempuan dengan mendirikan Korps Wanita Pejuang atau Laskar Wanita dan Kesatuan Wanita Indonesia Sulawesi. ${ }^{3}$ Salah satu tokoh perempuan yang paling sering disebut dalam peristiwa ini adalah Corry Van Stenus, atau yang lebih sering disebut Mami Corry. Corry lahir pada tahun 1922 dengan nama Cornelia Van Stenus. Ia merupakan istri kedua Kahar Mudzakkar. Perempuan yang berasal dari Klaten ini, merupakan anak Adrian Van Stenus, pria berdarah belandaJerman yang bekerja di pabrik gula Gondang Winangun dan Supinah, seorang wanita Jawa yang berasal dari Sragen. Corry yang sempat mengenyam pendidikan di AMS A Yogyakarta, kemudian menikah dengan Kahar pada tahun 1947.

Tulisan ini berfokus pada usaha untuk menceritakan kehidupan serta peran Corry Van Stenus pada masa pemberontakan Kahar Mudzakkar dengan menggunakan metode studi pustaka dan wawancara. Hal ini menjadi penting untuk memperlihatkan bahwa pada peristiwa pemberontakan perempuan tidak hanya menjadi sosok pelengkap dalam cerita namun juga turut ikut serta di dalamnya. Tulisan ini diharapapkan dapat menghadirkan cerita perempuan dalam historiografi Indonesia khususnya dalam penulisan sejarah pemberontakan di Indonesia.

\section{Corry berangkat ke Sulawesi}

Pada tahun 1950 Pemerintah di Sulawesi sedang dalam proses penyelesaian konflik antara gerilyawan dan angkatan Darat. Kesatuan Gerilya Sulawesi Selatan

\footnotetext{
${ }^{2}$ Beberapa tulisan yang membahas tema ini adalah tulisan dari Bahar Mattalioe, Anhar Gonggong, Syarifuddin Usman MHD, Barbara Sillars Harvey, dan Juga Van Dijk, ini belum termasuk karya-karya terbaru, skripsi, tesis serta desertasi dengan tema mengenai pemberontakan Kahar Muzakkar di Sulawesi Selatan.

${ }^{3}$ C. Van Dijk, Darul Islam : sebuah pemberontakan (Jakarta : Graffiti, 1987) h.177 dan Anhar Gonggong, Abdul Qahhar Mudzakkar : dari patriot hingga pemberontak (Jakarta : Grasindo, 1992), h. 112.
} 
(KGSS) menuntut agar diberi tempat dalam APRIS dengan dasar bahwa mereka telah berjasa dalam usaha mempertahankan kemerdakaan Indonesia di Sulawesi. Saleh Shahban selaku pewakilan KGSS meminta agar penggabungan pasukan yang terdiri dari 10 batalion ini, dilakukan secara menyeluruh. ${ }^{4}$ Pada tanggal bulan Juni 1950, Kahar bersama dengan Mursito, wakil dari Bambang Supeno tiba di Makassar untuk menyelesaikan permasalahan ini. ${ }^{5}$

Kahar yang kedatangannya diharapkan dapat menyelesaikan konflik yang terjadi, ternyata tidak mendapat respon yang positif dari KGSS. Mereka tetap pada pendirian mereka. Mereka meminta penggabungan ke dalam APRIS secara penuh dengan Kahar Muzakkar sebagai komandannya. Kahar kemudian memilih untuk bergabung dengan pasukan KGSS. Pada tanggal 1 Juli 1950, ia bertemu dengan Kawilarang, membawa nama pasukan KGSS mengajukan permohonan pembentukan Brigade atau Resimen Hasanuddin di dalam TNI. ${ }^{6}$ Sayangnya permohonan ini kembali ditolak oleh Kawilarang. Hal ini yang membuat Kahar memutuskan untuk meninggalkan TNI dan melepas tanda pangkatnya depan Kawilarang. Malam harinya Kahar "diculik" oleh salah satu pemimpin KGSS, Andi Sose' dan dibawa ke Baraka, Enrekang. ${ }^{7}$

Masalah gerilyawan yang tak kunjung usai dan posisi Kahar yang tidak lagi dapat bergerak dengan bebas setelah dirinya memutuskan untuk masuk hutan membuatnya tidak dapat datang menjemput istrinya-istrinya ke Jawa. Ia mengutus seorang pasukan kepercayaannya bernama Hamzah Pangerang untuk menjemput istri dan anaknya di Jawa. Keputusan.Dengan amanah dari Kahar maka berangkatlah Hamzah Pangerang ke Jawa.Ia menjelaskan situasi dan kondisi di Sulawesi pada ke dua istri Kahar di Jawa. Siti Walinah memilih untuk tetap tinggal di Jawa bersama dengan ke-enam anaknya sedangkan Corry bersama dua puteranya setuju untuk ikut ke Sulawesi.Bersama dengan dua orang puteranya, dikawal Hamzah Pangerang berangkatlah Corry menuju Sulawesi. ${ }^{8}$

\footnotetext{
${ }^{4}$ Anhar Gonggong menyebutkan bahwa pasukan ini terdiri dari 10 batalion (Anhar Gonggong, , Abdul Qahhar Mudzakkar : dari patriot hingga pemberontak, h. 94)akan tetapi Bahar Mattalioe menyebutkan bahwa KGSS ini terdiri dari 12 Batalion, dikutip dari Bahar Mattalioe, Pemberontakan menempuh jalur kanan(Jakarta : Grasindo : 1994), h.131.

${ }^{5}$ BarbaraSillars Harvey, Pemberontakan Kahar Muzakkar dari tradisi ke DI/TII,(Jakarta:Grafiti pers, 1989), h. 174.

${ }^{6} \mathrm{Ibid}$.

${ }^{7}$ Syarifuddin Usman Mhd,Tragedi Patriot dan pemberontakan Kahar Muzakkar (Yogyakarta:Narasi, 2009), h.76 dan Barbara Sillars Harvey, Pemberontakan Kahar Muzakkar, h.175.

${ }^{8}$ Eril Aqamuz (Siti Maesaroh), Profil Abdul Qahhar Mudzakkar Patriot Pejuang Kemerdekaan Indonesia dan Syuhada NII/TII(Tangerang, Yayasan Al abrar, 2007), h.34.
} 


\section{Corry, sang "Siti Khadijah” Kahar Muzakkar}

Berpindah tempat tinggal ke Sulawesi membawa perubahan yang sangat besar dalam hidup Corry. Setelah tiba di Sulawesi , Corry tidak tinggal di Makassar. Ia ikut Kahar untuk menetap di daerah Barakka, perbatasan antara kabupaten Luwu dan Enrekang. Selain harus beradaptasi dengan kebudayaan, bahasa dan tata krama yang berbeda dengan daerah asalnya. Ia juga harus beradaptasi dengan makanan. Corry yang sehari-harinya mengkonsumsi roti harus membiasakan diri untuk makan makanan lain. Di awal-awal keberadaannya di Sulawesi, Malinrang, bapak dari Kahar harus berusaha mencari roti kemana-mana agar Corry bisa makan. ${ }^{9}$

Selain harus menyesuaikan diri dengan lingkungan baru, Corry dihadapkan pada kenyataan bahwa suaminya telah kawin gantung dengan perempuan bernama Sitti Djanuari. Pernikahan keduanya terjadi 3 bulan sebelum Corry datang ke Sulawesi. Corry yang saat itu sedang hamil tidak menerima.Kahar tidak pernah membicarakan mengenai hal ini padanya, dan jelas tidak meminta izin darinya.

Pada tahun 1950-an, ketika Salawati Daud bertemu dengan Kahar, Ia sempat diajak oleh Corry untuk duduk ditengah semak-semak. Mereka berbincang hingga tiba pada saat Corry berlinang air mata. Ia menceritakan kisahnya yang ketika datang dari Jawa harus menghadapi kenyataan bahwa suaminya telah kawin dengan perempuan lain. Corry juga menceritakan dirinya mendapat surat dari Djanuari yang meminta agar Ia dapat menikah dengan Kahar. ${ }^{10}$ Salawati yang mendengar cerita tersebut sebisa mungkin menghibur Corry yang saat itu tengah sedang hamil besar agar tidak larut dalam kesedihan. Kahar yang melihat beban yang harus ditanggung oleh istrinya, mengasuh 3 orang anak, sembari harus berusaha beradaptasi dengan tempat baru ditambah dengan beban batin karena tidak terima dimadu, akhirnya memutuskan untuk menceraikan Sitti Djanuari pada tahun 1952. ${ }^{11}$ Corry kemudian kembali menjadi istri Kahar satu-satunya.

Namun, statusnya ini tidak bertahan lama. Kahar menikah lagi dengan seorang perempuan bernama Sitti Haliah setelah Ia melangkahkan kaki dalam perjuangan di Sulawesi. ${ }^{12}$ Sitti Haliah merupakan perempuan yang dikenal Kahar dengan baik. Ia merupakan bagian dari keluarga bangsawan di Luwu yang mempelopori masuknya Islam di Luwu. Setelahnya, Kahar menikah lagi dengan Sitti Rawe, yang diberi julukan oleh Kahar sebagai "Istri Famili” karena berasal dari dari kampung yang sama dengan Kahar. Corry kembali dimadu dengan seorang

\footnotetext{
${ }^{9}$ Wawancara dengan ibu Kanti (Istri Abdullah, anak ke-4 Corry Van Stenus) 16 September 2018 di Bekasi pukul 16.00-20.00 WIB.

${ }^{10}$ Koran Marhein edisi 24 September 1955 hlm. 1 dalam Sitti Maryam. "Salawati Daud dan Gagasan Tentang Persatuan Nasional Indonesia, Sebuah Biografi Politik : 1909-1985”, tesis-S2, program studi Ilmu Sejarah Fakultas Ilmu budaya Universitas gadjah Mada Yogyakarta. 2009, 267.

${ }^{11}$ Surat Kahar untuk istri-istrinya tanggal 20 Syawal $1380 \mathrm{H}$ yang diketik ulang oleh Andi Mudzakkar (arsip keluarga), h. 1.

${ }^{12}$ Ibid.
} 
janda bernama Siti Hamie yang pada awalnya dijodohkan dengan Kahar saat ia duduk di Standandschool Muhammadiyah Palopo. Kemudian Kahar menikah lagi dengan tiga 3 perempuan lain masing-masing bernama sitti Habibah, Andi Tenri Liwang dan Sitti Hudayah. Sejak tahun 1950 hingga tahun 1964, Corry telah dimadu dengan delapan 8 orang perempuan. Hubungan Corry dan istri-istri Kahar yang lain terjalin baik. Sepertinya Posisi Corry sebagai istri tertua membuat Ia menjadi disegani. Siti Riwayati menuturkan bahwa ibunya dengan istri-istri Kahar yang lain akur, justru kadang-kadang ketika ada perselisihan antara istri-istri yang lain Corry yang bertindak sebagai penengah. ${ }^{13}$

"Dalam kehidupan bapak, Mami Corry adalah istri yang paling setia dan paling mengerti keinginan suaminya untuk berpoligami. Beberapa kali mami Cory turut serta melamarkan calon istri buat suaminya,termasuk saat melamar ibu saya, Andi Siti Habiba, yang jadi istri kelima"14

Selain turut ikut melamar calon istri dari suaminya, Corry juga ikut terlibat dalam mempersiapkan pernikahan Kahar dengan calon istrinya yang lain. Saat suaminya akan menikah dengan Hudayah misalnya. Corry memandikan Daya, nama kecil Hudayah, dengan tangannya sendiri sebelum, perempuan yan berasal dari suku Marunene, Sulawesi Tenggara ini menikah dengan Kahar sebagai istri ke9. ${ }^{15}$

Di awal ketika Ia baru saja tiba di Sulawesi, Corry menunjukkan ketidaksetujuannya pada keputusan Kahar yang menikah lagi. Bahar Mattalioe menuliskan :

"Corry djuga berontak ketika dia akan dipoligamikan, tapi apa dajanja-dia hanja seorang wanita jang lemah. Minta tjerai karena dipoligamikan, diapun takut diadili apalagi dia turut menandatangani program poligami itu karena paksaan suaminya. Tegasnja menolak poligami tidak ada djalan sebab sudah mendjadi keputusan. Dia mau lari meninggalkan suaminja lari kemana? Dia dipagari oleh pengawal-pengawal Kahar jang bersusun-susun"16

Namun pada akhirnya Corry menunjukkan sikap berkompromi bahkan mendukung poligami yang dilakukan oleh suaminya.Sulit untuk menemukan alasan dibalik sikap Corry ini. Namun sepertinya Corry menerima tindakan Kahar

\footnotetext{
${ }^{13}$ Wawancara dengan Siti Riwayati(anak ketiga Corry Van Stenus) 17 April 2018 di Jakarta pukul 15.00-17.30 WIB.

${ }^{14}$ Mengutip penyataan dari Buhari Qahar Mudzakkar (Putera Kahar dengan Sitti Habibah) Pedoman Rakyat, edisi Minggu 2 April 2006.

${ }^{15}$ Kholis Bahtiar Bakri. Ragam "Kahar Mudzakkar : isyarat dari gunung Kamiasu”, Majalah Gatra edisi 10 Februari 2001, h. 53.

${ }^{16}$ Bahar Mattalioe, Kahar Muzakkar dengan Petualanganja(Jakarta:Intisa, 1965),h. 62.
} 
ini karena Ia melihat bahwa pernikahan Kahar dengan istri-istri setelah dirinya selalu punya alasan-alasan praktis. Alasan yang paling terlihat adalah ketika Kahar menikahi Sitti Hamie, seorang janda yang menguasai perdagangan kopra di Sulawesi Tenggara. Dengan bantuan Sitti Hamie dan saudaranya, Kahar dapat melakukan perdagangan kopra ke Singapura. Dilaporkan setidaknya Kahar melakukan perdagangan ini dua kali yakni pada tahun 1955 dan tahun 1957 melalui Tawao. ${ }^{17}$ Hasil dari penjualan kopra ini diperuntukkan untuk membeli perlengkapan berupa senjata api.

Kahar dan Corry menyadari bahwa anak-anak mereka sudah sampai pada usia sekolah. Gerakan DI/TII memang memiliki sekolah tapi sebagai orang tua dengan latar pendidikan yang baik, mereka menyadari bahwa anak-anak mereka berhak mendapatkan pendidikan yang terbaik. Di Makassar maupun di Jawa terdapat banyak sekolah dengan kualitas baik, namun dengan posisi Kahar seperti saat ini membuat pilihan mengirim anak-anak mereka ke Jawa ataupun Makassar tidak dapat dilaksanakan. Alhasil, keduanya memutuskan untuk mengirim anak-anak mereka ke luar negeri untuk belajar.

Menetapnya Corry di Sulawesi menjadikan dirinya mengalami banyak hal yang tentu saja tidak mudah untuk dia hadapi. Ia harus beradaptasi dengan lingkungan dan gaya hidup, merawat anak, dan berbagi suami dengan 8 orang perempuan lainnya. Melihat hal itu Kahar, kemudian memberi julukan Siti Hadijah pada sosok Corry.

"Corrie V. Stenus saya beri nama St. Hadjijah oleh karena kesetiaan, kesabaran keikhlasan, kesanggupan dan kesediannya melupakan kehidupan mewah yang dialaminya dan turut serta merasakan segala macam penderitaan,perjuangan menegakkan agama ISLAM bersama-sama dengan saja, sejak di Jawa sampai di Sulawesi" 18

\section{Corry sebagai "Srikandy Islam"}

Pada tahun 1952, Kahar diangkat menjadi panglima Divisi IV Tentara Islam Indonesia (TII) yang merupakan bagian dari pemberontakan DI/TII yang dipimpin oleh Kartosuwirjo. ${ }^{19}$ meskipun demikian, Kahar baru mengumumkan

\footnotetext{
${ }^{17}$ Harian Rakyat,edisi 18 Januari 1958, hlm. 2.

${ }^{18}$ Surat Kahar Muzakkar untuk istri-istrinya tanggal 20 Sawal $1380 \mathrm{H}$, diketik kembali oleh Andi Mudzakkar (Arsip Keluarga), hlm. 3. Sebagai suami sepertinya Kahar senang memberi julukan pada istri-istrinya. Sebenarnya julukan siti Hadijah juga ia berikan pada istrinya yang lain yakni Siti Hamie atas keikhlasannya merelakan hartanya untuk mendukung gerakan Kahar Muzakkar. Istri lain yang mendapatkan julukan adalah Siti Rawe. Ia diberi julukan sebagai "Istri Famili" karena ia berasal dari wilayah kelahiran Kahar dan masih tergolong famili.

${ }^{19}$ C. Van Dijk, Darul Islam : sebuah pemberontakan,h. 175.
} 
secara resmi penggabungan wilayah kekuasaannya ke dalam daerah DI/TII Jawa Barat setahun setelahnya.

Tidak semua orang mendukung perubahan ideologi dan organisasi gerakan yang dilakukan oleh Kahar. Hal ini menjadikan dirinya kemudian membentuk beberapa lembaga untuk menarik simpati rakyat. Ia mendirikan partai yang ia namai Partai Islam revolusioner, Barisan Tani Revolusioner dan juga organisasi untuk perempuan yang ia namai gerakan Wanita Islam Revolusioner. ${ }^{20}$ Khusus untuk organisasi perempuan yang ia dirikan, diserahkan kepada istrinya, Corry van Stenus.

Bahar Mattalioe menulis bahwa Kahar menginginkan kaum perempuan untuk tidak usah banyak bicara, tidak usah banyak protes dan ikut saja kemauan laki-laki. ${ }^{21}$ Namun sepertinya hal ini tidaklah demikian mengingat bahwa dalam gerakannya Kahar justru mendirikan Gerakan Wanita Islam Revolusioner yang diketuai oleh Corry Van Stenus.

Sebenarnya selain Gerakan Wanita Islam Revolusioner, terdapat beberapa nama lain yang digunakan untuk merujuk pada organisasi wanita DI/TII Sulawesi Selatan yakni Gerakan Wanita Indonesua (GERWIN), Kesatuan Wanita Indonesia Sulawesi (KWIS), Korps Wanita Pejuang atau Laskar Wanita. ${ }^{22}$

Tidak jelas apakah nama-nama yang disebutkan tadi merupakan organisasi yang berbeda atau Gerakan Wanita dibawah Gerakan Wanita Islam Revolusioner ataukah beragam nama tersebut merupakan variasi nama yang merujuk pada gerakan Wanita Islam Revolusioner. Namun orang-orang lebih akrab dengan nama Gerwais untuk menyebut organisasi wanita yang dibentuk untuk menarik perhatian perempuan-perempuan di Sulawesi Selatan dan bergabung ke dalam DI/TII. ${ }^{23}$

Organisasi ini berusaha mempersatukan perempuan-perempuan di daerah khususnya wilayah pedalaman sulawesi. Para anggota organisasi ditugaskan untuk mencari obat-obatan serta menarik perhatian masyarakat khususnya anggota TNI untuk ikut masuk sebagai anggota DI/TII. Anggota dari gerakan ini kebanyakan merupakan murid SMP, SMA, SGA dan juga guru. ${ }^{24}$

\footnotetext{
${ }^{20}$ Anhar Gonggong, Abdul Qahhar Mudzakkar, h. 109.

${ }^{21}$ Bahar Mattalioe, Kahar Muzakkar dengan petualanganja, h. 63.

22 Anhar Gonggong, Abdul Qahhar Mudzakkar,h. 109-112 dan Syarifuddin Usman Mhd,op.cit, 93-94.

${ }^{23}$ Bahar mattalioe dalam tulisannya Pembrontakan Menempuh Jalur Kanan menyebut bahwa istrinya adalah ketua GERWAIS Daerah III Lereng Cinta, (Bahar Mattalioe, Pemberontakan Menempuh Jalur Kanan, h. 195.) Hasan Kamal juga menyebut organisasi perempuan yang didirikan oleh DI/TII bernama GERWAIS (Wawancara dengan Hasan Kamal, 17 April 2018 pukul 13.00. 15.00 WIB di Jakarta)

${ }^{24}$ Anhar Gonggong,Abdul Qahhar Mudzakkar, h. 112.
} 
Dalam kepengurusan Gerwais, selain Corry sebagai ketua juga terdapat cabang-cabang Gerwais yang berada di markas DI/TII yang tersebar di berbagai wilayah. Posisi ketua cabang sepertinya ditempati oleh istri-istri dari pemimpin di markas tersebut. Hal ini terlihat dari posisi Sitti Hamry, istri Bahar Mattalioe, sebagai Ketua Cabang Gerwais di wilayah Gattareng Mattinggi. ${ }^{25}$

Sebagai organisasi yang bergerak dibidang sosial, Gerwais juga memperhatikan aspek penting yakni pendidikan. Gerwais memiliki sekolah Kepandaian Puteri yang didirikan di pegunungan Gattareng Mattinggi selatan desa Wanua Waru yang menjadi wilayah markas Bahar Mattalioe. ${ }^{26}$ Dengan mendatangkan berbagai peralatan sekolah dari kota, Sekolah ini mengajarkan pelajaran- pelajaran baik teori maupun praktek mengenai berbagai keterampilan puteri seperti menyulam dan menjahit. Letak sekolah yang berada di pegunungan menjadikan para siswa yang berasal dari berbagai daerah kekuasaan DI/TII ini ditampung di asrama sehingga mereka tidak perlu menempuh jarak yang jauh untuk ke sekolah. SKP Gerwais ini mengadakan pendidikan selama 6 bulan. ${ }^{27}$

Para siswi yang telah menyelesaikan pelajarannya kemudian dikirim kembali ke daerah mereka masing-masing untuk memanfaatkan keterampilan yang telah dipelajari. Sayangnya tidak ditemukan infomasi lebih lanjut apakah selain SKP di daerah Gattareng Mattinggi terdapat SKP milik Gerwais di daerah lainnya. Tapi tidak menutup kemungkinan terdapat sekolah lain mengingat bahwa DI/TII Sulawesi Selatan memang memiliki sekolah-sekolah yang didirikan di daerah kekuasaan mereka.

Dalam menjalankan sekolah, DI/TII biasanya menggunakan bangunan sekolah milik pemerintah yang proses belajar-mengajarnya tidak dapat berjalan karena masalah keamanan. Di daerah Rante Bella, Luwu terdapat laporan bahwa sekolah di daerah pegunungan ini sejak tahun 1952 berhenti beroperasi. ${ }^{28}$ Dilaporkan sekolah-sekolah di daerah ini dibuka hari minggu dan ditutup hari jumat. Terdapat proses belajar mengajar yang dikelola oleh DI/TII. Hanya saja tidak disebutkan apakah proses belajar mengajar yang berlangsung ini ditujukan untuk murid Sekolah Rakyat, Sekolah Menengah atau Menengah Atas.

Gerwais bergerak dibidang sosial dan juga pendidikan namun tidak menutup kemungkinan organisasi ini juga mendidik kader-kadernya untuk dapat ikut aktif di medan pertempuran. Hasan Kamal, putera tertua Corry Van Stenus menuturkan

\footnotetext{
${ }^{25}$ Bahar Mattalioe, Pemberontakan Menempuh Jalur Kanan, h. 196.

${ }^{26}$ Ibid., h. 195.

${ }^{27}$ Ibid.,h. 196

${ }^{28}$ Surat Kementrian Agama RI Kantor Urusan Agama Kabupaten Luwu-Palopo yang ditujukan pada Kepala Kantor Urusan Agama Provinsi Sulawesi di Makassar nomor 36/R/A/6/54 tanggal 27 Januar 1954. Arsip prov. Sulawesi tahun 1946-1960 (rahasia) nomor register 538 tahun
} 1954 volume 13 lembar dos nomor 36. 
bahwa para anggota Gerwais juga mengikuti pelatihan militer dan juga dipersenjatai. ${ }^{29}$ Tidak ditemukan arsip atau tulisan mengenai hal ini, namun jika ini benar, maka ini menjelaskan munculnya nama laskar wanita untuk menyebut gerakan wanita DI/TII Sulawesi Selatan.

Posisi Corry sebagai ketua gerakan ini tak dapat dipisahkan dari sosok suaminya. Corry yang merupakan seorang muallaf dan juga perempuan Indo-Jawa dapat memimpin perempuan-perempuan di Sulawesi tanpa adanya keberatan dari pendukung Kahar. Meskipun kualitas pribadi Corry Van Stenus yang setidaknya telah menempuh pendidikan di AMS dan Handelschool di Jawa bisa jadi menjadi salah satu faktor pendukung dirinya yang notabene merupakan orang luar dapat diterima untuk menjadi ketua gerakan perempuan ini. Kurangnya sumber menyebabkan tidak adanya informasi mengenai sejauh apa peranan Corry dalam pengembangan organisasi ini.

Sebagai perempuan, Corry cukup vokal dalam menyuarakan keberatannya pada hal-hal yang ia tidak setujui. Setelah bergabung sebagai bagian dari DI/TII, Kahar mencetuskan pemberlakuan Piagam Makkalua yang mengatur kehidupan para anggotanya. Piagam Makkalua ini mengatur kehidupan anggota gerakan untuk hidup dengan sederhana dan tidak berlebih-lebihan. Konsep yang dipakai yakni "kepentingan kelompok harus didahulukan dari kepentingan pribadi". Piagam ini mengatur dengan sangat detail mengenai kehidupan para anggota mulai dari aturan batas memegang uang tunai, penggunaan gelar bangsawan dan harta benda seperti emas dan berlian, bahkan hingga pelarangan mengkonsumsi rokok impor dan makanan seperti coklat dan susu. ${ }^{30}$ Selain itu piagam ini juga mengatur mengenai batas mahar pernikahan, bahkan menganjurkan poligami.

Corry dan para perempuan pendukung gerakan Kahar jelas menolak ide ini. Mereka membantah dan tidak setuju dengan keputusan adanya imbauan Poligami. ${ }^{31}$ Sayangnnya permintaan mereka tidak dikabulkan dan pasal mengenai penganjuran poligami tetap dimasukkan dalam dalam piagam Makkalua. Pada bab VII terdapat pasal yang menganjurkan para penanggung jawab para janda yang suaminya meninggal dunia, untuk mencarikan jodoh bagi mereka. Selanjutnya di bab IX disebukan bahwa bagi para penentang poligami akan diadili di depan pengadilan. ${ }^{32}$

Tidak lama setelah piagam Makkalua diberlakukan Kahar menyatakan akan menikah dengan Andi Haliah, seorang cucu dari Datu Luwu. Corry yang melihat hal ini mempertanyakan niatan suaminya. Corry menentang ide Kahar dengan

\footnotetext{
${ }^{29}$ Wawancara dengan pak Hasan Kamal 17 April 2018 di Jakarta pukul 13.00-15.00 WIB.

${ }^{30}$ C. Van Dijk,Darul Islam : sebuah pemberontakan, h.180-181.

${ }^{31}$ Bahar Mattalioe, Kahar Muzakkar dengan Petualanganja, h. 61-62.

${ }^{32}$ Ibid., h. 84-85.
} 
alasan bahwa Andi Haliah bukanlah seorang janda. Padahal berdasarkan pada Piagam Makkalua yang poligami yang dianjurkan adalah poligami untuk membantu para janda yang suaminya meninggal di medan perang.

Kahar yang mendengar keberatan istrinya menyatakan bahwa pernikahannya dengan Andi Haliah merupakan tindakan untuk menunjukkan sikap Kahar sebagai sosok anti feodal. Ia ingin menunjukkan bahwa orang biasa seperti dirinya dapat menikah dengan golongan bangsawan seperti Andi Haliah. Ketika Kahar menyatakan niatnya untuk menikah lagi, Corry kembali menanyakan alasan Kahar hingga akhirnya ketika Kahar menikah lagi untuk keempat kalinya Corry sudah tidak lagi bersuara. Di tahun $1380 \mathrm{H}$. atau tahun 1960, Kahar kembali rujuk dengan Sitti Djanuari kemudian menikah lagi dengan beberapa perempuan seperti yang telah disebutkan sebelumnya. Sikap diam Corry sepertinya merupakan bentuk kompromi dirinya atas tindakan Kahar.sepertinya Ia sudah melihat bahwa pernikahan Kahar dengan perempuan-perempuan setelahnya memiliki alasan praktis.

Diluar perannya sebagai ketua Gerwais, Corry sering disebut sebagai wakil Kahar. Sebagai istri, dirinya diberi gelar sebagai "istri perjuangan" atau "Srikandy Islam”. ${ }^{33}$ Saat melamar Corry, Kahar sudah menyampaikan jelas niatannya untuk membawa calon istrinya itu berjuang ke Sulawesi.

"Corie Van Stenus saya peristrikan sebagai istri kedua dari St. Walinah di Jawa, dengan dasar perhitungan yang berlandasan pokok pada rasa cintah kasih saya terhadap Islam. Dan perikemanusiaan, bahwa saya seorang muslim revolusioner sangat ingin meninggalkan pusaka kenangan pada anak keturunan saya pada hususnya dan keada masyarakat dunia pada umumnya untuk menyakinkan kepada masyarakat dunia bahwa Islam bukan keturunan segolongan manusia akan tetapi diperuntukkan oleh Tuhan untuk keseluruhan lapisan masyarakat dunia di seluruh permurkaan bumi dengan tidak membeda-bedakan keturuan bangsa manusia" ${ }^{34}$

Beberapa kali Corry diutus Kahar untuk melakukan perjalanan membawa pesan suaminya untuk pemerintah. Pada tanggal 27 September 1961 ia membawa surat pribadi Kahar untuk Presiden Soekarno setelah sebelumnya terlebih dahulu bertemu dengan M. Jusuf di Makassar. ${ }^{35}$ Pertemuan Corry dengan M. Jusuf menghasilkan kesepakatan bahwa Jusuf Akan menemani Corry menuju Jakarta

\footnotetext{
${ }^{33}$ Surat Kahar Muzakkar untuk istri-istrinya tanggal 20 Syawal 1380 H, diketik kembali oleh Andi Mudzakkar (arsip keluarga), h. 1.

${ }^{34}$ Ibid.

${ }^{35}$ Barbara Sillars Harvey, Pemberontakan Kahar Muzakkar, h.319.
} 
untuk bertemu dengan Soekarno. ${ }^{36}$ Maka Corry bersama Abdullah, puteranya yang masih berusia 7 tahun berngkat ke Jakarta dengan pesawat Elekta. ${ }^{37}$

Dalam pertemuan antara Corry, Jusuf dan Nasution ini, Jusuf meyakinkan Kepala Staf Angkatan Darat ini bahwa keputusan untuk menerima kembali Kahar adalah suatu keputusan yang bijaksana, maka kembalilah Corry ke Sulawesi membawa kabar akan diadakannya perundingan pada tahun yang sama di Bonepute. ${ }^{38}$ Pada tanggal 21 Oktober 1961, Jusuf bersama Azis Taba tiba di Bonepute yang disambut oleh Ayah Kahar dan juga Corry beserta Gerungan. ${ }^{39}$

Dalam pertemuann di Bonepute ini, Corry tidak hanya menyambut namun juga mengantar Jusuf menuju ke markas besar Kahar. ${ }^{40}$ Pertemuan kedua terjadi pada November 1961 yang menghasilkan kesepakatan bahwa seluruh pasukan Kahar berada dibawah komando Jusuf kecuali Momoc Ansarullah. Setelah kesepakatan ini, beberapa pasukan Kahar akhirnya memasuki kota. Corry sempat akan berangkat lagi ke Jakarta untuk membahas mengenai perundingan di Bonepute mengingat masih ada hal yang mengganjal di hati Kahar. Sayangnya keberangkatan Corry kali ini gagal. M. Jusuf mengeluarkan surat perintah untuk menangkap Corry. ${ }^{41}$

Sebagai perempuan, peran Corry yang tidak terbatas pada tugas domestik. Untuk menunjang perannya di sektor publik, Corry melatih dirinya sehingga ia dapat mengendarai kuda dengan gesit. ${ }^{42}$ Rumah Corry di Lompobulu daerah yang terletak di perbatasan Wajo dan Sidrap digunakan sebagai pusat pemerintahan dan juga tempat menerima tamu. ${ }^{43}$ Saat menjadi kurir pembawa surat dari Kahar, ia menyamar dengan menggunakan pakaian pria. ${ }^{44}$ Kegesitan Corry juga di diakui oleh Rompas, seorang wartawan senior koran Pedoman Rakyat. Ia yang saat itu juga ikut dalam perundingan antara Jendral M. Jusuf dan Kahar di Bonepute mengatakan "saat itu saya menyaksikan Corry terlihat cukup gesit dan tak pernah jauh dari puteranya Abdullah". ${ }^{45}$ Sayangnya setelah perundingan ini masih terdapat hal yang tidak memuaskan Kahar sehingga dirinya memilih untuk tetap berada di

${ }^{36}$ Jo' Kojongiang, Mengenang Perjuangan bersama Abdul Qahhar Mudzakkar dan J.W Gerungan (Makassar :La Galigo Multimedia, 2010), h. 47.

${ }^{37}$ Corry Van Stenus. Suka Duka dan Pengalaman Corry disamping Suami Qahar Mudzakkar 31 Desember 1990, (arsip keluarga), h. 8.

${ }^{38}$ Barbara Sillars Harvey, Pemberontakan Kahar Muzakkar,h. 320.

${ }^{39}$ Ibid.

${ }^{40} \mathrm{Ibid}$.

${ }^{41}$ Corry Van Stenus,Suka Duka dan Pengalaman Corry,h. 10.

${ }^{42}$ Wawancara dengan ibu Fitri 16 Mei 2018 (keponakan Corry anak pertama Frans Van Stenus) pukul 11.00-15.00 WIB.

${ }^{43}$ Jo’ Kojongiang,Mengenang Perjuangan bersamaAbdul Qahhar Mudzakkar, h. 85.

${ }^{44}$ Ibid.

${ }^{45}$ Pedoman Rakyat edisi minggu 2 April 2006, 3. 
hutan. Ia kemudian mengutus Corry untuk kedua kalinya ke Jakarta namun sayangnya gagal. Jendral M. Jusuf mengeluarkan surat perintah penangkapan untuk Corry Van Stenus. Dirinya sempat menjadi tahanan di rumah Dr. Natsir atas perintah dari Jendral M. Jusuf bersama dengan Abdullah. Selama berada di rumah ini, Corry sempat mengajari anak-anak Dr. Natsir mengaji, sholat serta sikap sopan santun kepada orang tua. ${ }^{46}$

Untuk kabur dari penahanan ini, Kahar melalui salah satu pasukannya menghubungi Corry mengenai rencana, waktu dan lokasi penjemputan dirinya dan Abdullah.Diawal, Corry memberitahu keluarga Dr. Natsir bahwa Abdullah pada waktu itu sempat disekolahkan, ingin menghadiri acara ulang tahun temannya. Dr. Natsir mengiyakan maka berangkatlah Abdullah ke acara tersebut. ${ }^{47}$ Corry baru menyusul kemudian ketika dirinya telah terlebih dahulu memberi para penjaga bir dan membuat mereka mabuk. Saat para penjaga lengah, keluarlah Corry yang menggunakan pakaian layaknya noni Belanda dari rumah tersebut. ${ }^{48}$ Di tempat yang ditentukan dirinya dijemput oleh pasukan Kahar. Kaburnya Corry kemudian diketahui oleh para penjaga, mereka dikejar hingga ke hutan namun para pengejar tidak dapat menangkap rombongan Corry.

Selain menjadi kurir surat, Corry juga terlibat dalam pembuatan surat. Seorang mantan pendukung Kahar yang menyebut diri sebagi Putera Rimba mengirim surat kepada pemerintah Indonesia. Dalam surat tersebut ia menyatakan diri sebagai pejuang yang bergabung dengan Kahar Mudzakkar dan kemudian menyesalinya. Putera Rimba menuturkan bahwa Kahar termasuk antek-antek Belanda yang diperkuat oleh istri Kahar yakni Corry yang aktif mengirim surat dengan keluarganya di Semarang dan Nederland yang mendirikan gerwin atau Gerwais untuk menyebarkan pengaruh Van Der Palas. ${ }^{49}$

Jo' Kojongiang menceritakan bahwa saat dirinya yang waktu itu menjadi tahanan pasukan DI/TII pimpinan Kahar, dikirimi surat oleh Corry untuk menemuinya di rumahnya di Kampung Betteng. ${ }^{50}$ Setelah tinggal di rumah Corry, Jo' seringkali diminta untuk mengetik surat atas permintaan Corry Van Stenus. Putra Rimba menyatakan bahwa Corry aktif berkirim surat dengan saudara-

${ }^{46}$ Ibid,Sepertinya penahanan ini terjadi di akhir tahun 1962 atau 1963, jika menilik dari tahun terjadinya pertemuan di Bonepute. Dalam tulisan ini disebut Corry menjadi tahanan rumah selama dua tahun. Namun dalam wawancara dengan ibu Kanti selaku menantu dari Corry, ia menyatakan bahwa penahanan ini tidak sampai setahun. (wawancara dengan Ibu Kanti di Bekasi 16 September 2018 pukul 16.00-20.00 WIB)

${ }^{47}$ Wawancara dengan Ibu Kanti (Istri Abdullah, anak ke-4 Corry) di Bekasi 16 September 2018 pukul 16.00-20.00WIB.

${ }^{48} \mathrm{Ibid}$.

49 Surat dari Putera Rimba,Arsip provinsi Sulawesi nomor register 324 tahun 1953-1954 volume 363 dos no 40 .

${ }^{50}$ Jo' Kojongiang, Mengenang Perjuangan bersamaAbdul Qahhar Mudzakkar, h. 29. 
saudaranya, namun anak-anak Corry menuturkan bahwa ibunya tidak menjalin komunikasi dengan keluarganya selama di Sulawesi, bahkan dirinya dianggap telah meninggal dunia oleh keluarganya di Jawa karena minimnya komunikasi. ${ }^{51}$ Sepertinya surat-surat yang diketik Corry merupakan surat yang ditujukan untuk organisasi.

\section{Berpisah dengan Kahar}

Pada tahun 1964, ketika Kahar mundur ke Lasolo, Kolaka Sulawesi Tenggara, Corry tidak ikut bersama dengan suaminya. Ia bersama Abdullah memilih untuk tinggal di kampung Sumiling, Masamba Luwu Utara. ${ }^{52}$ Kahar menggantar istri dan anaknya tersebut ke salah satu puncak gunung Kambiasu. Diatas gunung ini ia mengucapkan kata perpisahan sambil memeluk istri dan anaknya.

"Istriku, barangkali inilah pertemuan kita yang terakhir di dunia ini. Selanjutnya, biarlah kita bertemu di akhirat. Jaga kesehatanmu Corry. Bimbing dan pelihara anakmu baik-baik, agar jadi anak saleh. Bertakwalah pada Allah"53

Ketika pamflet mengenai kematian Kahar tersebar, Corry segera bergegas untuk melihat jenazah suaminya. Sayangnya M.Jusuf tidak membolehkan Corry untuk melihat Kahar untuk terakhir kalinya. Hanya ada dua anak Kahar yang sempat melihat jenazah bapaknya yakni Abdullah Ashal dan Farida bersama suaminya Andi Semangat. ${ }^{54}$ Mereka melihat Kahar yang disemayamkan di Rumah Sakit Plamonia sebelum di makamkan.Tidak ada satupun yang mengetahui letak makam Kahar. Hal ini menimbulkan kontroversi bahwa sebenarnya Kahar masih hidup. Namun bagi Corry, kematian suaminya merupakan suatu hal yang pasti. Ia makin yakin bahwa orang yang tertembak oleh Sadeli di pinggir sungai Lasolo adalah suaminya ketika ia mendengar anak-anaknya mengatakan ada bekas eksem di kaki, leher serta cambang suaminya. ${ }^{55}$

Meninggalnya Kahar mengakhiri perjuangannya selama 15 tahun. Satu persatu para pendukung, kerabat serta keluarga Kahar melaporkan diri ke pemerintah.Termasuk Corry dan Abdullah yang melapor pada bulan februari 1965. Keluarga besar Kahar sempat berkumpul di Lanipa sebelum akhirnya Corry dan puteranya dikembalikan oleh Jendral Jusuf ke keluarganya di Klaten.

\footnotetext{
${ }^{51}$ Wawancara dengan Bapak Hasan Kamal dan ibu Siti Riwayati di Jakarta17 April 2018 pukul 13.00-1730 WIB.

${ }^{52}$ Harian Palopo Pos edisi senin 3 April 2006,h. 7.

53 Kholis Bahtiar Bakri, Ragam "Kahar Mudzakkar : Isyarat Dari Gunung Kamiasu", Majalah Gatra edisi 10 Februari 2001,h. 50.

${ }^{54}$ Ibid.

${ }^{55}$ Ibid.
} 


\section{Kesimpulan}

Corry Van Stenus menjadi satu dari banyak perempuan yang terlibat dalam cerita pemberontakan Kahar Mudzakkar. Selama pemberontakan berlangsung, Corry ikut serta membantu baik dari sektor domestik maupun diluar sektor domestik. Di sektor domestik ia menjadi istri yang setia menemani suaminya berjuang. Atas kesabaran dan ketabahannya, Kahar menjulukinya sebagai Siti Khadijah.

Di sektor non-domestik, Corry menjadi ketua gerakan wanita Islam Sulawesi (GERWAIS) yang didirikan oleh Kahar Mudzakkar setelah ia begabung dengan DI/TII. Selain itu, ia pernah menjadi utusan Kahar untuk membawa surat ke Presiden Soekarno di Jakarta dan menjadi orang yang menyambut tamu takkala terjadinya pertemuan di Bonepute.

\section{DAFTAR PUSTAKA}

Corry Van Stenus. Suka Duka dan Pengalaman Corry disamping Suami Qahar Mudzakkar.31 Desember 1990, (arsip keluarga).

Surat Kahar untuk istri-istrinya tanggal 20 Syawal $1380 \mathrm{H}$ yang diketik ulang oleh Andi Mudzakkar (arsip keluarga).

Surat Kementrian Agama RI Kantor Urusan Agama Kabupaten Luwu-Palopo yang ditujukan pada Kepala Kantor Urusan Agama Provinsi Sulawesi di Makassar nomor 36/R/A/6/54 tanggal 27 Januar 1954. Arsip prov. Sulawesi tahun 1946-1960 (rahasia) nomor register 538 tahun 1954 volume 13 lembar dos nomor 36.

Surat dari Putera Rimba,Arsip provinsi Sulawesi nomor register 324 tahun 1953-1954 volume 363 dos no 40.

Harian Rakyat,edisi 18 Januari 1958.

Harian Palopo Pos 3 April 2006.

Majalah Gatra 10 Februari 2001.

Pedoman Rakyat 2 April 2006.

Aqamuz, Eril (Siti Maesaroh). 2007.Profil Abdul Qahhar Mudzakkar Patriot Pejuang Kemerdekaan Indonesia dan Syuhada NII/TII. Tangerang, Yayasan Al abrar.

Dijk , C. Van. 1987. Darul Islam : sebuah pemberontakan. Jakarta : Graffiti. 
Gonggong, Anhar.1992.Abdul Qahhar Mudzakkar : dari patriot hingga pemberontak. Jakarta : Grasindo.

Harvey, Barbara Sillars. 1989. Pemberontakan Kahar Muzakkar dari tradisi ke DI/TII. Jakarta:Grafiti pers.

Kojongiang, Jo'. 2010. Mengenang Perjuangan bersama Abdul Qahhar Mudzakkar dan J.W Gerungan. Makassar : La Galigo Multimedia.

Maryam, Siti. 2009. "Salawati Daud dan Gagasan Tentang Persatuan Nasional Indonesia, Sebuah Biografi Politik : 1909-1985”, tesis-S2, program studi Ilmu Sejarah Fakultas Ilmu budaya Universitas gadjah Mada Yogyakarta..

Mhd, Syarifuddin Usman.2009.Tragedi Patriot dan pemberontakan Kahar Muzakkar. Yogyakarta:Narasi.

Mattalioe, Bahar.1965.Kahar Muzakkar dengan Petualanganja. Jakarta:Intisa.

Mattalioe, Bahar. 1994. Pemberontakan menempuh jalur kanan. Jakarta : Grasindo.

\section{Wawancara}

H. Hasan Kamal Said Qahhar Mudzakkar (Anak Pertama Corry).

Siti Riwayati (Anak ketiga Corry).

Kantina Jembawati (Menantu Corry, Istri Abdullah).

Larastri (Ipar Corry, Istri Frans Van Stenus).

Fitriana (keponakan Corry, Anak pertama larastri- Frans).

Verasari (keponakan Corry, Anak kedua Larastri-Frans). 